\title{
ANALYSIS OF FAST NEUTRON TRANSPORT IN CHLORIDE SALTS USING MONTE CARLO METHOD
}

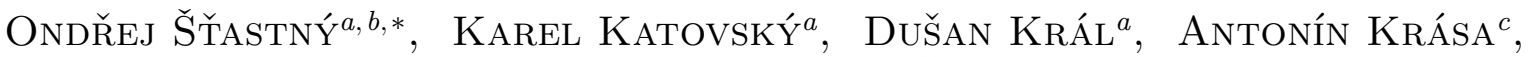 \\ CABle Kurwitz $^{d}$, Kamil ŠTevanka ${ }^{a}$ \\ ${ }^{a}$ Brno University of Technology, Faculty of Electrical Engineering and Communication, Department of \\ Electrical Power Engineering, Technická 10, 61600 Brno, Czech Republic \\ ${ }^{b}$ State Office for Nuclear Safety Department of Non - Proliferation, Senovážné náměstí 9, 11000 Prague, \\ Czech Republic \\ ${ }^{c}$ Belgian Nuclear Research Centre, Institute for Advanced Nuclear Systems, SCK CEN, Boeretang 200, 2400 \\ Mol, Belgium \\ ${ }^{d}$ Texas A\&M University, Department of Nuclear Engineering, AI Engineering Building 3133, 423 Spence St, \\ College Station, TX 77843, United States \\ * corresponding author: xstast30@vutbr.cz
}

\begin{abstract}
The aim of this paper is to present results of fast neutron behavior analysis within the chloride salts environment using simulations based on Monte Carlo method (MCNP 6.2). Three non-fueled salts $\left(\mathrm{NaCl}, \mathrm{KCl}, \mathrm{MgCl}_{2}\right)$ and two salts containing fissile material $\left(\mathrm{UCl}_{3}, \mathrm{ThCl}_{4}\right)$ were studied. Results of this theoretical study will be used for design of an experimental assembly, which will serve to achieve goals of the international research project ADAR (Accelerator Driven Advanced Reactor). One of the project objectives is to investigate chloride salts as potential coolant and a dissolved fuel carrier of advanced nuclear reactor cooled by molten salts and driven by an accelerator.
\end{abstract}

KEYWORDS: Accelerator driven systems, fast neutrons, ADAR, chloride salts, MCNP, molten salt reactors, Monte Carlo simulations.

\section{INTRODUCTION}

Molten Salt Reactors (MSRs) have been identified as promising reactor technology with regard to thorium fuel cycle or for transmutation of spent nuclear fuel from light water reactors. There are several designs based on fuel dissolved in the molten salt coolant, such as fluorides or chlorides [1].

This article is focused on fast neutron behavior analysis within the chloride salts, since they have good nuclear, chemical and physical properties and are much easier to treat. They usually form solutions with lower melting point, and they have higher solubility for actinides. As a result, they can contain significant amounts of transuranic elements. On the other hand, the major isotope of chlorine, Cl-35 gets activated to Cl-36, long-lived energetic beta emitter, so Cl-37 is much preferable in a reactor [1].

As stated above, the goal is to perform studies with fast neutron spectrum since it is used in fast spectrum MSRs (MSFRs) and or accelerator driven systems [2]. They can have conversion ratios within range burner - converter - breeder. Furthermore, they can be optimized for burning minor actinides, for breeding plutonium from U-238, or they may be opencycle power plants since the fast neutron spectrum allows the possibility to omit onsite processing to remove transuranic elements. Since the fission products have relatively large neutron capture cross sec- tions in thermal energies, the capture cross sections at higher energies is much lower, resulting in much greater fission product build-up in an MSFR than in a thermal-spectrum MSR. Higher absorption rate at fission products nuclei in thermal-spectrum MSR leads to fission products transmutation and therefore they get closer to the valley of stability (after appropriate decay). Moreover, the fuel salt heavily loaded with fission products can be sent occasionally for batch processing or allowed to solidify and be disposed of in a repository. For full breeder configuration the fissile material needs to be progressively removed [1].

Recent research [3] shows significant discrepancies between evaluated nuclear data libraries in the fast neutron region. Improving fast neutron data for chloride salts is essential requirement for the ADAR project (Accelerator Driven Advanced Reactor with molten chloride salt fuel coolant $)^{1}$. In order to perform such neutronic research, a theoretical study of an experimental assembly consisting of a fast neutron source in chloride salt environment was performed with the aim to optimize parameters for an experimental campaign using activation detectors.

In the following sections, the model is of experimental assembly is described, the current status of

\footnotetext{
${ }^{1}$ Detailed project information available at https://starfos.tacr.cz/en/project/LTAUSA18198.
} 


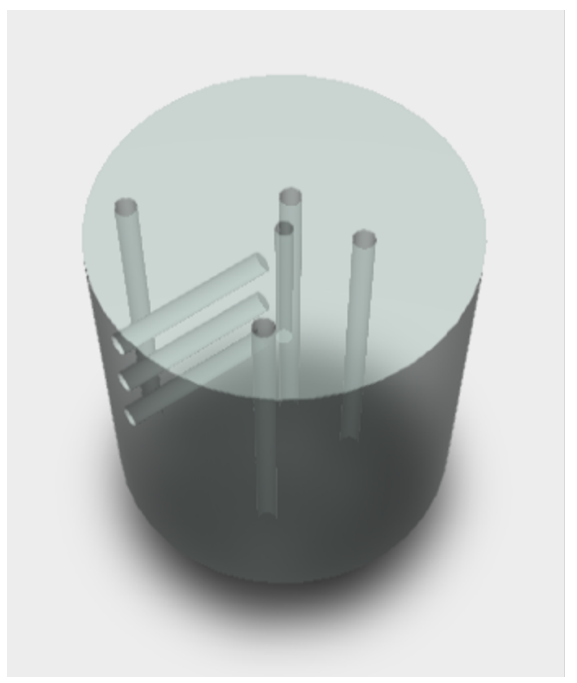

Figure 1. Salt experimental assembly "Solnicka" 3D model

relevant nuclear data is summarized and then Monte Carlo calculations of neutron transport through chloride salts are presented.

\section{DESIGN OF SALT EXPERIMENTAL ASSEMBLY}

\subsection{MATERIAL}

In order to study neutronic properties of most commonly available chloride salts, a design of a salt experimental assembly "Solnicka" (in English "salt cellar") has been proposed (Fig. 1). The assembly is cylindrical shape with diameter of $50 \mathrm{~cm}$ and height of 60 $\mathrm{cm}$ with coating from stainless steel (304 type, thickness of $0.6 \mathrm{~mm}$ on sides, $1 \mathrm{~mm}$ at the bottom and top cover). It contains the following channels (coated with $0.6 \mathrm{~mm}$ thick steel layer):

- one central channel for neutron source $(22 \mathrm{~mm}$ in diameter) which extends from top to the middle of the height $(30 \mathrm{~cm})$,

- four axial experimental channels $(28.1 \mathrm{~mm}$ in diameter) leading from to the top to the bottom located at radial distance of $5,10,15$ and $20 \mathrm{~cm}$ from the vertical axis,

- three radial experimental channels $(28.1 \mathrm{~mm}$ in diameter) at heights of 35, 45 and $55 \mathrm{~cm}$ above the bottom. Their length is $23 \mathrm{~cm}$ spanning from the outer surface of the assembly in direction to the vertical axis.

The experimental channels have been filled with vacuum for simplicity and in order to avoid influence of other materials. As a source of neutrons, the AmBe source (cylinder with diameter of $19 \mathrm{~mm}$ and height of $40 \mathrm{~mm}$ ) located in the middle height $(30 \mathrm{~cm})$ with emission rate of $5.5615 \times 10^{6}$ neutrons/s was considered since it emits fast neutron field $(0.1-11 \mathrm{MeV}$, see Table 1 for probability distribution function (PDF)

\begin{tabular}{llll}
\hline $\mathbf{E}[\mathrm{MeV}]$ & PDF & $\mathrm{E}[\mathrm{MeV}]$ & $\mathrm{PDF}$ \\
\hline $4,14 \mathrm{E}-07$ & $0,00 \mathrm{E}+00$ & $5,68 \mathrm{E}+00$ & $2,33 \mathrm{E}-02$ \\
$1,10 \mathrm{E}-01$ & $1,44 \mathrm{E}-02$ & $5,89 \mathrm{E}+00$ & $2,06 \mathrm{E}-02$ \\
$3,30 \mathrm{E}-01$ & $3,34 \mathrm{E}-02$ & $6,11 \mathrm{E}+00$ & $1,82 \mathrm{E}-02$ \\
$5,40 \mathrm{E}-01$ & $3,13 \mathrm{E}-02$ & $6,32 \mathrm{E}+00$ & $1,77 \mathrm{E}-02$ \\
$7,50 \mathrm{E}-01$ & $2,81 \mathrm{E}-02$ & $6,54 \mathrm{E}+00$ & $2,04 \mathrm{E}-02$ \\
$9,70 \mathrm{E}-01$ & $2,50 \mathrm{E}-02$ & $6,75 \mathrm{E}+00$ & $1,83 \mathrm{E}-02$ \\
$1,18 \mathrm{E}+00$ & $2,14 \mathrm{E}-02$ & $6,96 \mathrm{E}+00$ & $1,63 \mathrm{E}-02$ \\
$1,40 \mathrm{E}+00$ & $1,98 \mathrm{E}-02$ & $7,18 \mathrm{E}+00$ & $1,68 \mathrm{E}-02$ \\
$1,61 \mathrm{E}+00$ & $1,75 \mathrm{E}-02$ & $7,39 \mathrm{E}+00$ & $1,68 \mathrm{E}-02$ \\
$1,82 \mathrm{E}+00$ & $1,93 \mathrm{E}-02$ & $7,61 \mathrm{E}+00$ & $1,88 \mathrm{E}-02$ \\
$2,04 \mathrm{E}+00$ & $2,23 \mathrm{E}-02$ & $7,82 \mathrm{E}+00$ & $1,84 \mathrm{E}-02$ \\
$2,25 \mathrm{E}+00$ & $2,15 \mathrm{E}-02$ & $8,03 \mathrm{E}+00$ & $1,69 \mathrm{E}-02$ \\
$2,47 \mathrm{E}+00$ & $2,25 \mathrm{E}-02$ & $8,25 \mathrm{E}+00$ & $1,44 \mathrm{E}-02$ \\
$2,68 \mathrm{E}+00$ & $2,28 \mathrm{E}-02$ & $8,46 \mathrm{E}+00$ & $9,68 \mathrm{E}-03$ \\
$2,90 \mathrm{E}+00$ & $2,95 \mathrm{E}-02$ & $8,68 \mathrm{E}+00$ & $6,52 \mathrm{E}-03$ \\
$3,11 \mathrm{E}+00$ & $3,56 \mathrm{E}-02$ & $8,89 \mathrm{E}+00$ & $4,26 \mathrm{E}-03$ \\
$3,32 \mathrm{E}+00$ & $3,69 \mathrm{E}-02$ & $9,11 \mathrm{E}+00$ & $3,67 \mathrm{E}-03$ \\
$3,54 \mathrm{E}+00$ & $3,46 \mathrm{E}-02$ & $9,32 \mathrm{E}+00$ & $3,81 \mathrm{E}-03$ \\
$3,75 \mathrm{E}+00$ & $3,07 \mathrm{E}-02$ & $9,53 \mathrm{E}+00$ & $5,06 \mathrm{E}-03$ \\
$3,97 \mathrm{E}+00$ & $3,00 \mathrm{E}-02$ & $9,75 \mathrm{E}+00$ & $6,25 \mathrm{E}-03$ \\
$4,18 \mathrm{E}+00$ & $2,69 \mathrm{E}-02$ & $9,96 \mathrm{E}+00$ & $5,52 \mathrm{E}-03$ \\
$4,31 \mathrm{E}+00$ & $2,86 \mathrm{E}-02$ & $1,02 \mathrm{E}+01$ & $4,68 \mathrm{E}-03$ \\
$4,61 \mathrm{E}+00$ & $3,18 \mathrm{E}-02$ & $1,04 \mathrm{E}+01$ & $3,70 \mathrm{E}-03$ \\
$4,82 \mathrm{E}+00$ & $3,07 \mathrm{E}-02$ & $1,06 \mathrm{E}+01$ & $2,78 \mathrm{E}-03$ \\
$5,04 \mathrm{E}+00$ & $3,33 \mathrm{E}-02$ & $1,08 \mathrm{E}+01$ & $1,51 \mathrm{E}-03$ \\
$5,25 \mathrm{E}+00$ & $3,04 \mathrm{E}-02$ & $1,10 \mathrm{E}+01$ & $3,63 \mathrm{E}-04$ \\
$5,47 \mathrm{E}+00$ & $2,74 \mathrm{E}-02$ & $1,11 \mathrm{E}+01$ & $0,00 \mathrm{E}+00$ \\
\hline & & &
\end{tabular}

TABLE 1. Energy spectra for considered AmBe neutron source according to ISO-8529-1 [5]

\begin{tabular}{ccc}
\hline Salt & Density $\left[\mathrm{g} / \mathrm{cm}^{3}\right]$ & $k_{\text {eff }}$ \\
\hline $\mathrm{PuCl}_{3}$ & 5.71 & $1.27283+/-0.00006$ \\
$\mathrm{UCl}_{3}$ & 5.50 & $0.12304+/-0.00001$ \\
$\mathrm{ThCl}_{4}$ & 4.59 & $0.01936+/-0.00000$ \\
$\mathrm{NaCl}$ & 2.18 & - \\
$\mathrm{KCl}$ & 1.98 & - \\
$\mathrm{MgCl}_{2}$ & 2.32 & - \\
\hline
\end{tabular}

TABLE 2. Results of multiplication coefficient calculation (using 250 cycles with $10^{6}$ particles from the source)

overview) standardized ISO-8529-1 [5] and can suitably serve for purposes of this study. To reach maximal homogeneity of the salt environment around the neutron source, a salt plug is considered to be placed above the source inside the source channel.

For purposes of this study, a model of salt experimental assembly has been created using MCNP 6.2 (see Fig. 2) [6]. Three non-fueled salts ( $\mathrm{NaCl}$, $\mathrm{KCl}, \mathrm{MgCl}_{2}$ ) and two salts containing fissile material $\left(\mathrm{UCl}_{3}, \mathrm{ThCl}_{4}\right)$ were studied using calculation of reaction rates for set of selected reactions (see Fig. 3). The non-fueled salts serve to investigate their potential influence on transport of neutrons (as a potential ternary salt coolant for nuclear reactors [7], [8], [9]). 

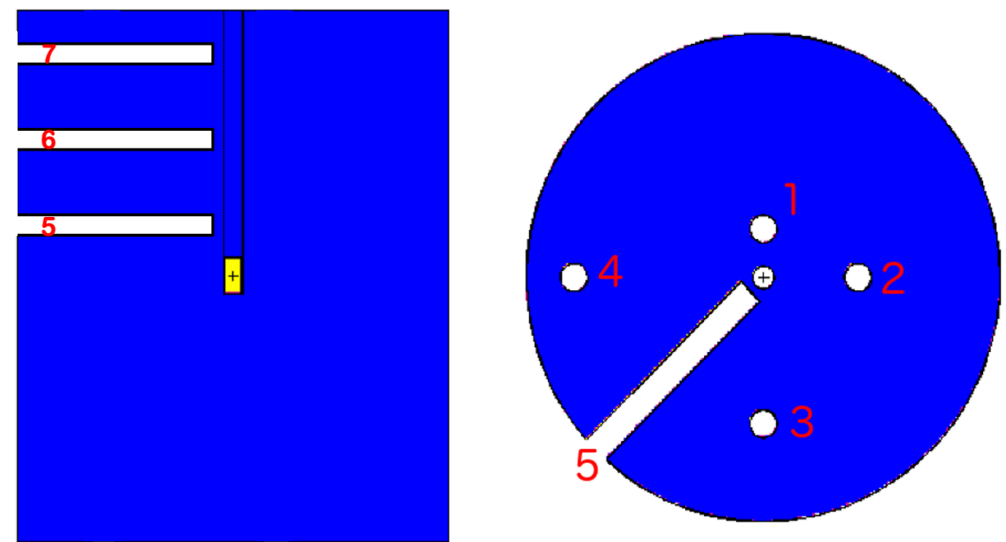

FiguRE 2. Salt experimental assembly "Solnicka" vertical and horizontal cross section at height of $35 \mathrm{~cm}$ (from the MCNP model); Nos. 1-4 are assigned to axial channels, 5-7 to radial channels
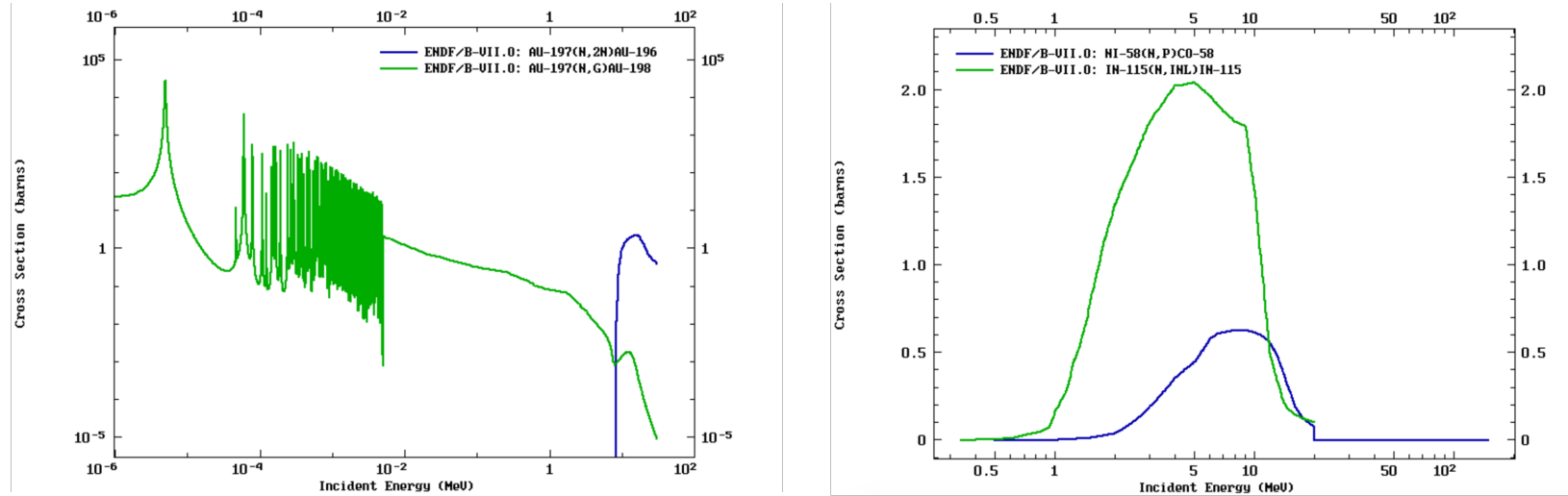

FiguRE 3. Cross sections of activation reactions [4]

$\mathrm{UCl}_{3}$ (with depleted uranium) and $\mathrm{ThCl}_{4}$ represent a chloride salt carrying nuclear material - as a reference chemical compound which could be used in a molten salt reactor, where the fuel is dissolved in the coolant. $\mathrm{PuCl}_{3}$ salt has also been considered, but salt assembly with abovementioned dimensions would be supercritical (see Tab. 2).

Activation foils were selected as neutron detectors. The chosen foil materials are $\mathrm{Ni}$, In and $\mathrm{Au}$. They are mainly mono-isotopic or with one strongly dominating isotope, therefore, the identification of the reaction channel from the observed product is expected to be unambiguous. Non-threshold and threshold reactions of these materials are shown in Fig. 3. Thanks to distribution of the threshold energies between 0.7 and $11.0 \mathrm{MeV}$ it will be possible to investigate sensitivity of activation to various parts of the fast component of the neutron field and their changes in the salt environment.

\section{Results AND Discussion}

Source driven calculations were carried out with MCNP 6.2 and using the ENDF/B-VII.0 evaluated nuclear data library. Radial and axial reaction rates from the Fig. 3 have been calculated in all experimental channels (numbers 1-4 are vertically sorted by increasing distance from central source channel, 5-7 are horizontally sorted by increasing height) with $10^{10}$ neutrons from the source (resulting in relative error of results lower than 0.01), see examples of the gold foil activation in the following figures. The observed trends are similar for different activation foil materials (differences are mainly in the absolute values). The results are presented in a systematic comparison in three groups:

- one salt, one foil material, one reaction - different radial and axial channels (Fig. 4);

- one salt, one foil material, one radial or axial channel - different reactions (Fig. 5 and Fig. 6);

- one radial or axial channel, one foil material, one reaction - different salts (Fig. 7 and Fig. 8)

The axial as well as radial distributions of nonthreshold $(\mathrm{n}, \gamma)$ reactions were found to be rather broad compared to the spatial distributions of threshold reactions, which are narrower, likely due to their higher sensitivity to the fast neutrons with energies greater than $1 \mathrm{MeV}$ that dominate in the vicinity of the AmBe source. In the axial channel closest to the source, the peak factor of the threshold reactions is about an order of magnitude bigger than that of the non-threshold reactions. In the contrary, the peak 

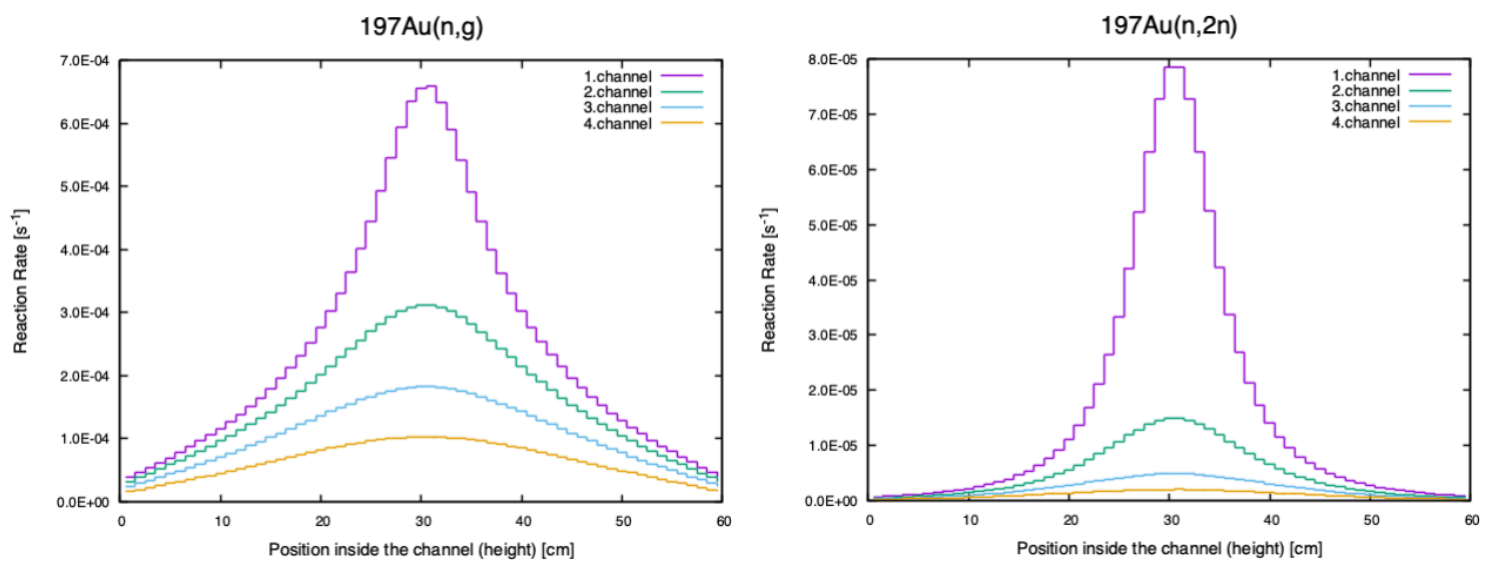

$197 \mathrm{Au}(\mathrm{n}, \mathrm{g})$
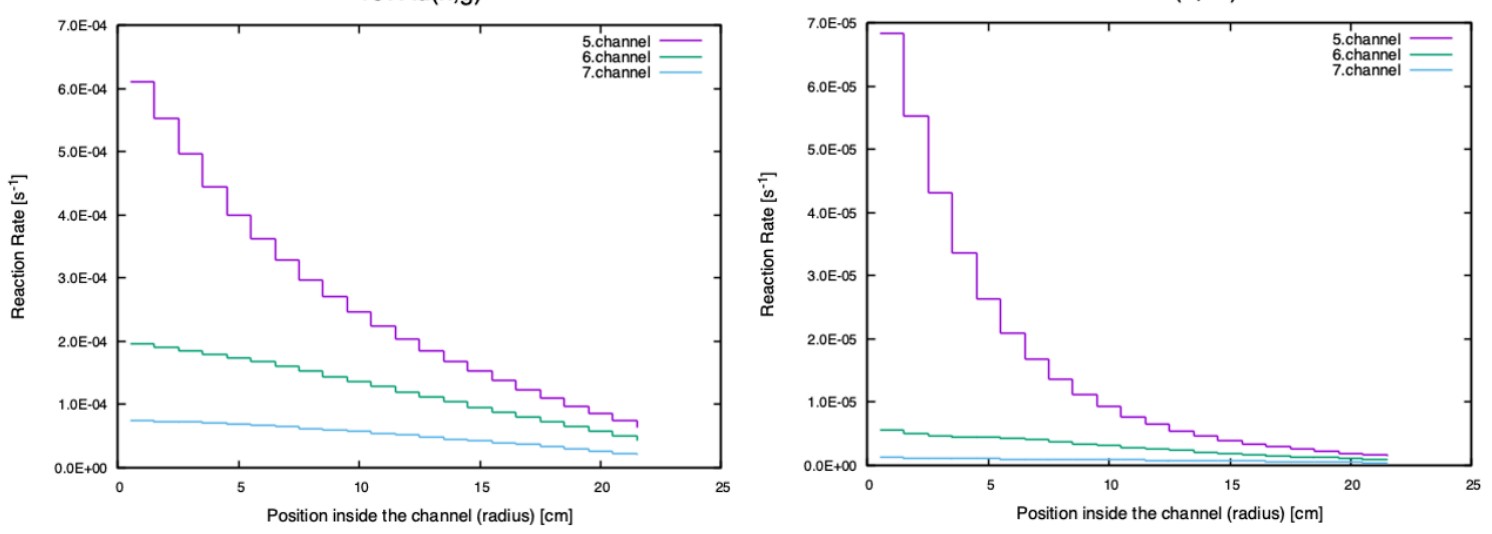

Figure 4. Axial (top) and radial (bottom) reaction rates of non-threshold (left) and threshold (right) activation reactions in gold foils in a $\mathrm{UCl}_{3}$ salt assembly

factors of both reaction types are very similar in the furthest axial channel.

In absolute terms, the reaction rates of the nonthreshold reactions are about one and two orders of magnitude bigger than those of the threshold reactions at the positions in the middle part of the assembly and on its boundaries, respectively.

Comparison of the spatial distributions of reaction rates in different salt environments provide an interesting comparison, see Fig. 7 and Fig. 8. The spatial distributions of non-threshold reactions strongly differ in different salt environments in any of the axial and radial channels. The most intensive low energy neutron field causing the biggest $(n, \gamma)$ rates was found to be, as expected, in the $\mathrm{UCl}_{3}$ salt, which contributes to the neutron field by fission. Somewhat surprisingly, the second most intensive low-energy neutron field was found in $\mathrm{NaCl}$, while $\mathrm{ThCl}_{4}$ is on the third place, which shows its rather small contribution of the fission neutrons (compare with $k_{\text {eff }}$ in Tab. 2). The weakest low-energy neutron field is in $\mathrm{KCl}$. The reaction rates in different salts differ up to a factor of 4 .

The threshold reactions corresponding to the fast neutron field component show completely different trends. In the channel closest to the neutron source the reaction rates are almost the same for any of the salt environments. With increasing distance of axial channels from the source, the threshold reaction rates start differing in various salts. The strongest fast neutron field was found to be in $\mathrm{KCl}$ while the weakest one in $\mathrm{UCl}_{3}$ and $\mathrm{ThCl}_{4}$. That suggests that the down-scattering and capture prevail over the fission neutron production in these fissile materials. This behaviour is valid for any of the reactions with threshold above $1 \mathrm{MeV}$, while the inelastic scattering in ${ }^{115} \mathrm{In}\left(\mathrm{E}_{t h} \approx 0.4 \mathrm{MeV}\right)$ represents a transition region between threshold and non-threshold reactions, see Fig. 9.

A strong influence of different salt composition can be also seen on specific behaviour in the radial channel furthest from the assembly centre, where the neutron leakage dominates causing a decrease in the threshold reaction rates for $\mathrm{KCl}, \mathrm{NaCl}$ and $\mathrm{MgCl}_{2}$, see Fig. 8. However, in $\mathrm{UCl}_{3}$ and $\mathrm{ThCl}_{4}$ fission locally prevails and causes the maximum to remain close to the assembly center axis. This will be especially interesting feature for comparison with the experiment.

\section{Conclusions}

Monte Carlo calculations of fast neutron transport through non-fueled salts $\left(\mathrm{NaCl}, \mathrm{KCl}, \mathrm{MgCl}_{2}\right)$ as well as neutron multiplication in salts containing fissile material $\left(\mathrm{UCl}_{3}, \mathrm{ThCl}_{4}, \mathrm{PuCl}_{3}\right)$ were performed. The 

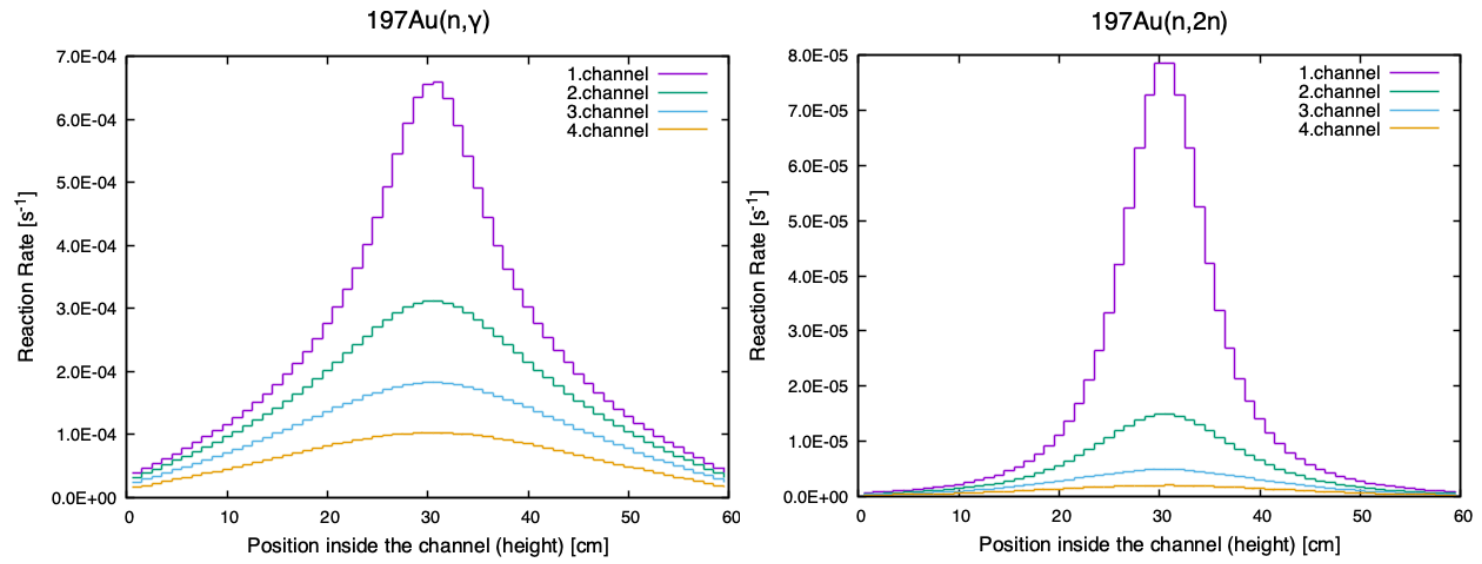

$197 \mathrm{Au}(\mathrm{n}, \mathrm{Y})$
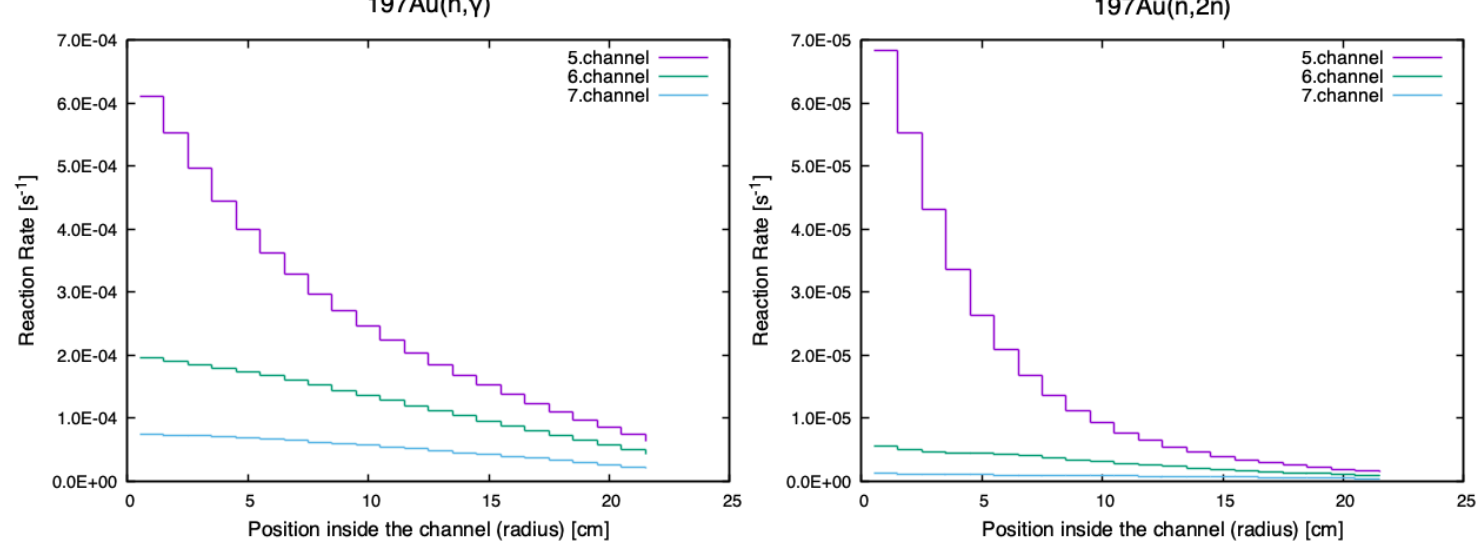

Figure 5. Axial reaction rates in gold foils in a $\mathrm{UCl}_{3}$ salt assembly

\section{Reaction rates at $\mathrm{Au}$}

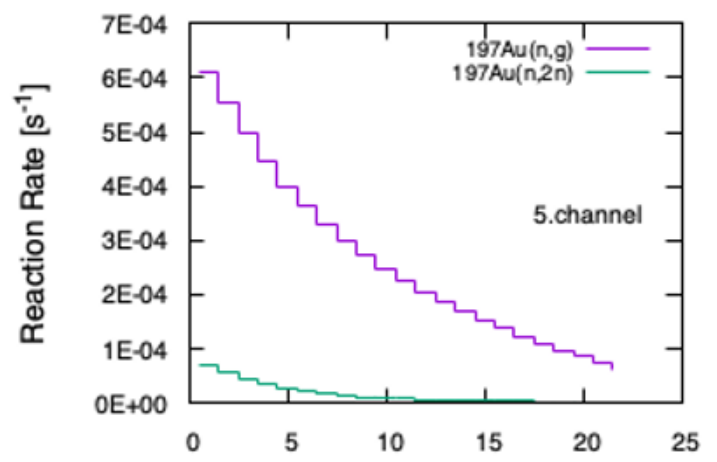

Position inside the channel (radius) [cm]

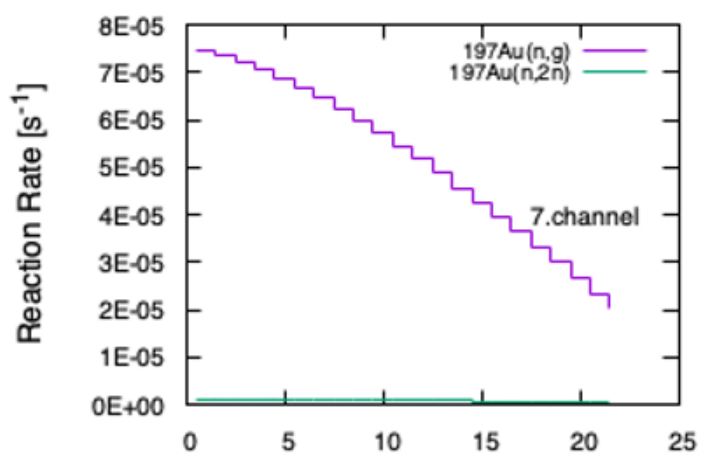

Position inside the channel (radius) [cm]

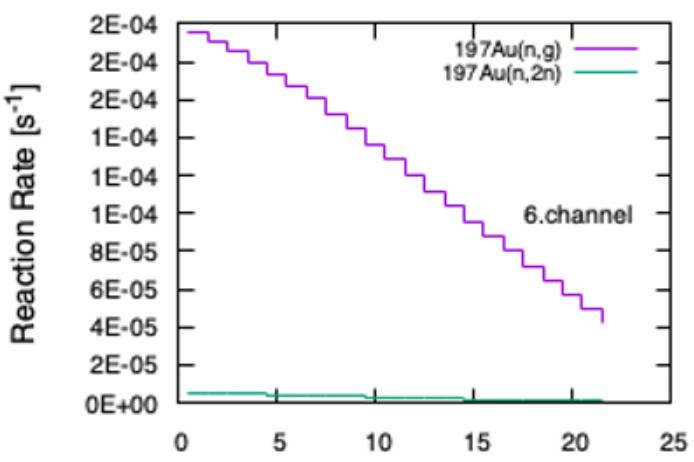

Position inside the channel (radius) [cm]

FIgURE 6. Radial reaction rates in gold foils in a $\mathrm{UCl}_{3}$ salt assembly 

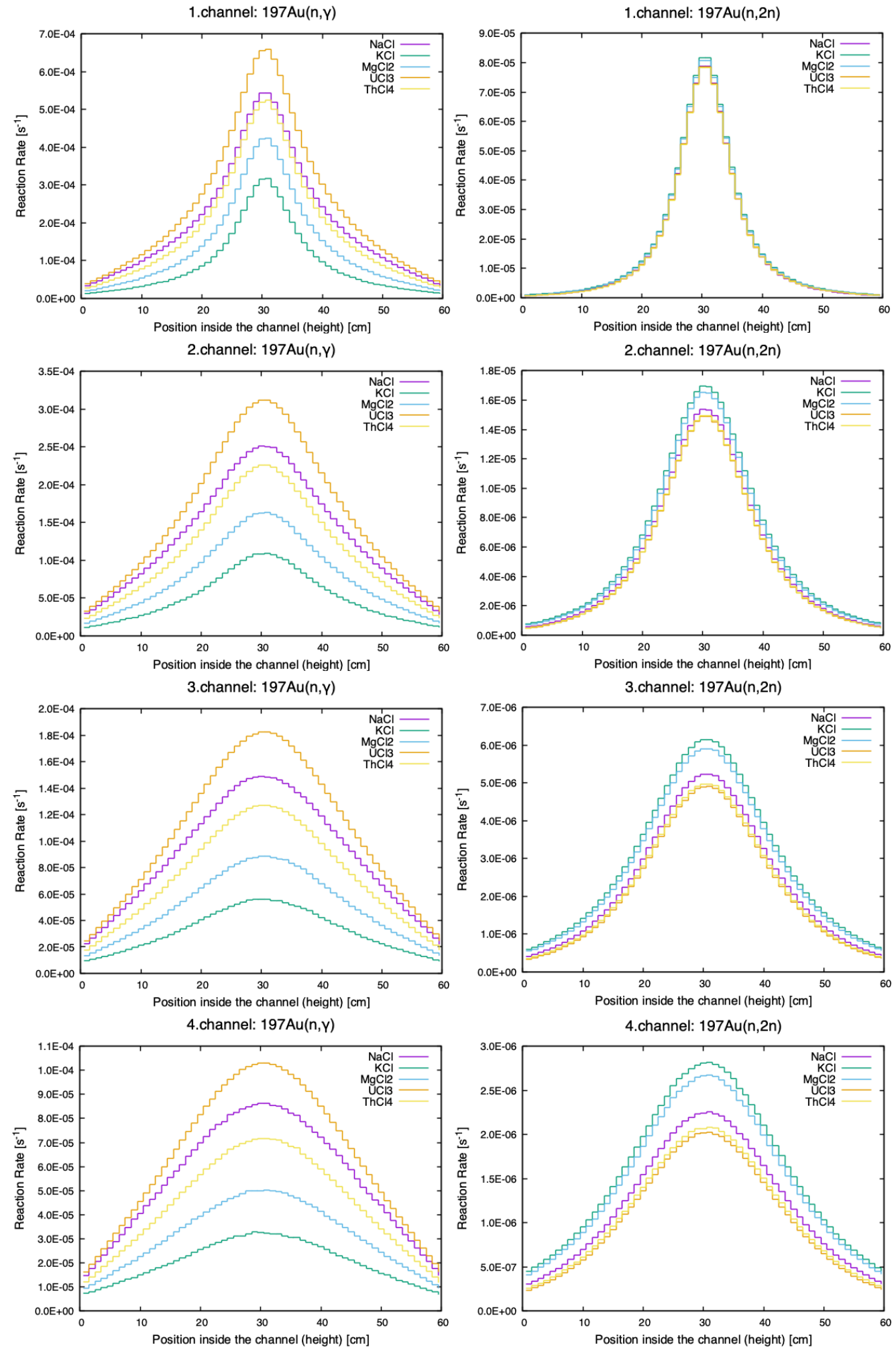

FiguRE 7. Axial reaction rates of non-threshold (left) and threshold (right) reactions in gold foils in five salt assemblies 

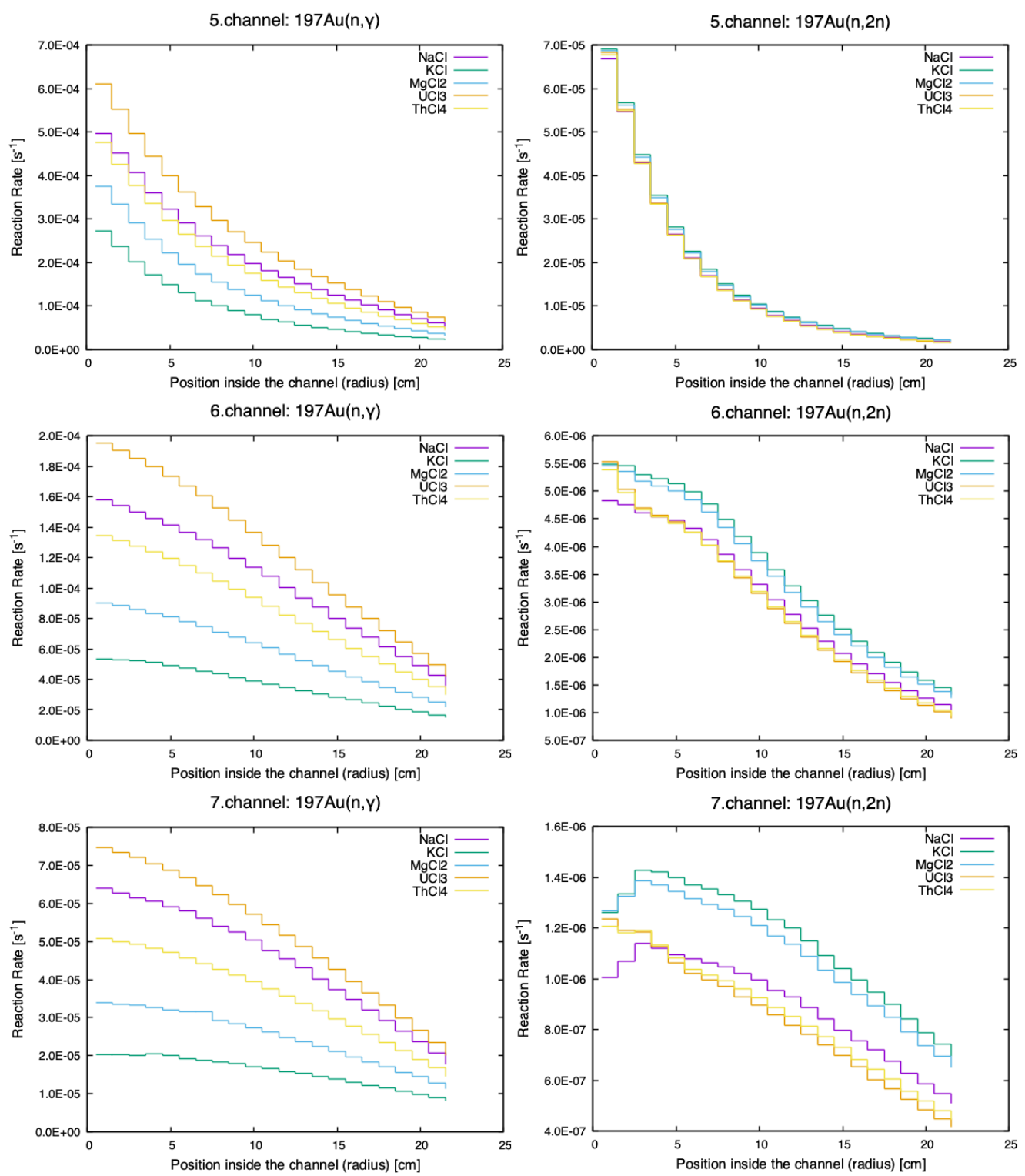

FIGURE 8. Radial reaction rates of threshold reactions in indium (left) and nickel (right) foils in five salt assemblies
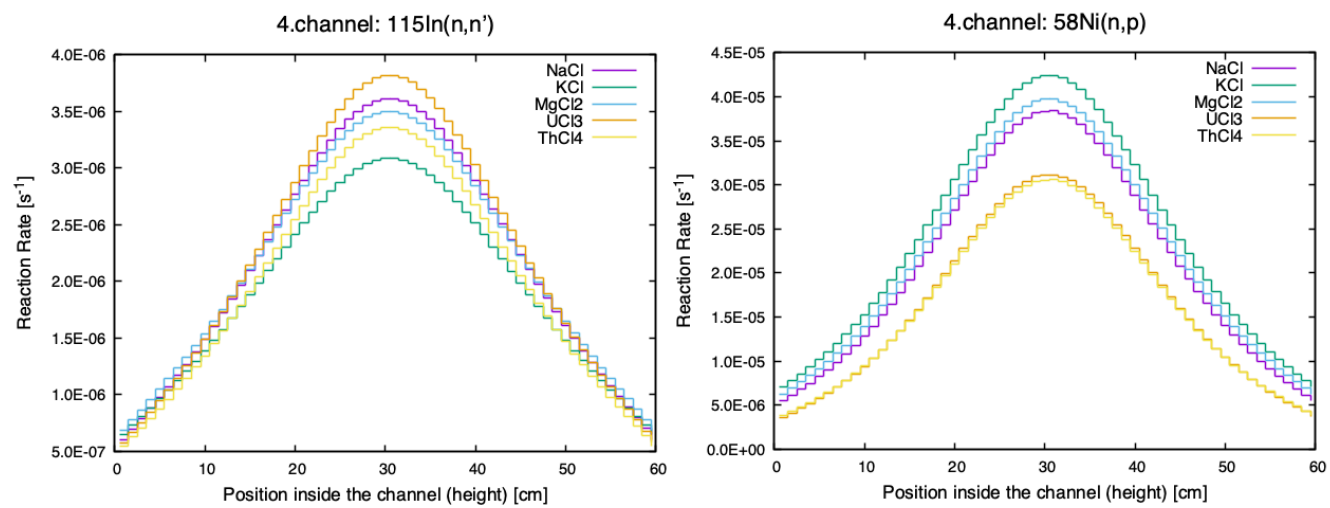

Figure 9. Axial reaction rates of threshold reactions in indium (left) and nickel (right) foils in five salt assemblies 
spatial distributions of threshold and non-threshold reactions in $\mathrm{Ni}, \mathrm{In}, \mathrm{Au}$ activation foils were investigated. All calculations have been so far performed using the ENDF/B-VII.0 library.

Based on presented calculation results for nonfueled salts, it can be stated, that $\mathrm{MgCl}_{2}$ or $\mathrm{KCl}$ should be more convenient if neutron fast spectrum is desired. On the other hand, $\mathrm{NaCl}$ shows higher moderation capabilities. Concerning salts fueled with $\mathrm{U}$ and Th, using of $\mathrm{ThCl}_{4}$ provides slightly higher yields of non-elastic reactions with higher threshold than the $\mathrm{UCl}_{3}$.

\section{ACKNOWLEDGEMENTS}

Authors gratefully acknowledge financial support from the Ministry of Education, Youth and Sports of the Czech Republic under international research cooperative program between Texas A\&M University, USA and the Brno University of Technology, Czech Republic ("ADAR - Accelerator Driven Advanced Reactor", LTAUSA18198).

\section{REFERENCES}

[1] Molten Salt Reactors. World Nuclear Association [online]. London, United Kingdom: World Nuclear Association, 2020 [cit. 2020-06-15] Available at: https: //www.world-nuclear.org/information-library/ current-and-future-generation/ molten-salt-reactors .aspx.

[2] P. Mcintyre, S. Assadi, K. Badgley, et al. Accelerator-driven subcritical fission in molten salt core: Closing the nuclear fuel cycle for green nuclear energy 1525:636-642, 2013. DOI:10.1063/1.4802405.
[3] J. C. Batchelder, S.-A. Chong, J. Morrell, et al. Possible evidence of nonstatistical properties in the ${ }^{35} \mathrm{Cl}(n, p){ }^{35} \mathrm{~S}$ cross section. Phys Rev C 99:044612, 2019. DOI:10.1103/PhysRevC.99.044612.

[4] M. Chadwick, P. Obložinský, M. Herman, et al. Endf/b-vii.0: Next generation evaluated nuclear data library for nuclear science and technology. Nuclear Data Sheets 107(12):2931 - 3060, 2006. Evaluated Nuclear Data File ENDF/B-VII.0, DOI:10.1016/j.nds.2006.11.001.

[5] International Organization for Standardization. ISO 8529-1:2001 Reference neutron radiations - Part 1: Characteristics and methods of production.

[6] C. J. Werner. MCNP User's Manual - Code Version 6.2. Los Alamos National Laboratory, report LA-UR-17-29981 (2017).

[7] E. Shwageraus, P. Hejzlar, M. Driscoll. Liquid salt cooled flexible conversion ratio fast reactor: Neutronic design. Nuclear Engineering and Design 239:26262645, 2009. DOI:10.1016/j.nucengdes.2009.07.011.

[8] N. E. Todreas, P. Hejzlar, A. Nikiforova, et al. Flexible conversion ratio fast reactors: Overview. Nuclear Engineering and Design 239(12):2582 - 2595, 2009. Flexible Conversion Fast Reactors Special Section with Regular Papers, DOI:https://doi.org/10.1016/j.nucengdes.2009.07.014.

[9] Y. Li, X. Xu, X. Wang, et al. Survey and evaluation of equations for thermophysical properties of binary/ternary eutectic salts from nacl, kcl, mgcl2, cacl2, zncl2 for heat transfer and thermal storage fluids in csp. Solar Energy 152:57 - 79, 2017. Progress in Solar Energy Special Issue: Concentrating Solar Power (CSP), DOI:10.1016/j.solener.2017.03.019. 